\title{
Enhancing thermal tolerance by eliminating the pejus range: a comparative study with three decapod crustaceans
}

\author{
Jennifer A. Jost ${ }^{1,2}$, Stephanie M. Podolski ${ }^{1}$, Markus Frederich ${ }^{1, *}$ \\ ${ }^{1}$ Department of Marine Sciences, University of New England, Biddeford, Maine 04005, USA \\ ${ }^{2}$ Present address: Biology Department, Bradley University, Peoria, Illinois 61625, USA
}

\begin{abstract}
Marine invertebrates in the intertidal and subtidal zones are often exposed to highly variable environmental conditions, especially rapid changes in temperature. The ability to survive at different temperatures has previously been described using an extended version of Shelford's law of tolerance, with optimum, pejus (Latin: 'turning worse'), and pessimum ranges, and the respective thresholds, critical $\left(T_{\mathrm{c}}\right)$ and pejus $\left(T_{\mathrm{p}}\right)$ temperatures, that mark the transition from one range into the next. The width of the pejus range, in which the scope for activity gradually declines, varies among species. We tested the hypothesis that the width of the pejus range is correlated to the temperature stability of the species' respective habitats. We used locomotor activity, heart rate, lactate accumulation, heat shock protein 70 (HSP70) levels, and the activation of AMPactivated protein kinase (AMPK) to identify $T_{\mathrm{c}}$ and $T_{\mathrm{p}}$ in 3 decapod crustaceans: green crab Carcinus maenas, rock crab Cancer irroratus, and lobster Homarus americanus. We found speciesspecific patterns of temperature-induced changes in all parameters, especially in HSP70 protein and AMPK activity. The width of the pejus range (between $T_{\mathrm{p}}$ and $T_{\mathrm{c}}$ ) was 8 to $12^{\circ} \mathrm{C}$ for rock crabs and 12 to $16^{\circ} \mathrm{C}$ for lobsters. Most importantly, green crab, the most temperature-tolerant of our 3 species and which lives in a highly variable habitat, switched directly from optimum to pessimum range, meaning that the pejus range was eliminated completely. Additionally, even lethal temperatures did not activate AMPK in green crabs, pointing to a different cellular tolerance strategy than in rock crabs and lobsters. This modified tolerance pattern might represent a broader strategy to enhance physiological tolerance in a highly variable habitat.
\end{abstract}

KEY WORDS: AMP-activated protein kinase - AMPK - Heat shock protein 70 - HSP70 Temperature stress $\cdot$ Critical temperatures

\section{INTRODUCTION}

Marine invertebrates are often exposed to varying temperatures and have evolved strategies to tolerate these changes. During severe heat stress, the failure of ventilatory or circulatory function results in a transition to anaerobic metabolism even if sufficient oxygen for aerobic metabolism is present in the environment. The threshold at which this transition occurs is defined as the critical temperature $\left(T_{\mathrm{c}}\right)$ (Zielinski \& Pörtner 1996). Survival beyond $T_{\mathrm{C}}$ is time-limited due to the low ATP yield of anaerobiosis that exacerbates the mismatch of energy supply and demand at extreme temperatures. This concept is supported by work on several marine invertebrate and fish species (for review see Pörtner 2002, 2010). The concept of $T_{\mathrm{C}}$ is consistent with Shelford's law of tolerance (Shelford 1931), which states that an animal or plant performs well in an optimum range for any given environmental parameter, such as temperature. Outside the optimum range, performance gradually declines, and is very poor in the pessimum 
ranges at both extremes. $T_{\mathrm{C}}$ characterizes the transition into the pessimum range. However, in its natural environment an animal is frequently exposed to suboptimal conditions, often well before $T_{\mathrm{c}}$ is attained. Consequently, Frederich \& Pörtner (2000) added 'pejus temperature' $\left(T_{\mathrm{p}}\right)$ and 'pejus range' (from the Latin for 'turning worse') to this concept. In the pejus range, which is between the optimum and pessimum ranges, animals can still survive, but with a reduced scope for aerobic activity. Subsequent studies have identified $T_{\mathrm{p}}$ and pejus ranges in various species of marine invertebrates and fish (reviewed by Pörtner 2010). $T_{\mathrm{p}}$ and $T_{\mathrm{c}}$ differ by several degrees, thus indicating a well-defined and broad pejus range. However, the width of the pejus range appears to vary among species, and the outstanding question of whether this is associated with habitat stability needs to be addressed.

In a previous study on the rock crab Cancer irroratus, we showed that $T_{\mathrm{p}}$ can be identified on the cellular level by the activity of AMP-activated protein kinase (AMPK; Frederich et al. 2009). AMPK is a well-characterized 'master switch' for cellular energy metabolism in mammals (Winder \& Hardie 1999). AMPK is thought to constantly monitor the energy status of a cell and to regulate the anabolic and catabolic processes to ensure a constant ATP concentration. The activation of AMPK prevents ATP depletion and promotes replenishing of the ATP pool by inhibiting ATP-consuming pathways such as the synthesis of glycogen, fatty acids, proteins, and cholesterol, and in parallel, accelerating ATP-producing pathways such as glucose uptake, glycolysis, and fatty acid $\beta$-oxidation. AMPK is highly conserved during evolution, and similar functions have been identified in mammals, birds, Caenorhabditis elegans, the fruit fly, yeast, and other species (for review see Karagounis \& Hawley 2009 or Hardie 2011).

For the present study, we investigated how the width of the pejus range varies in 3 decapod crustacean species with different habitat-usage patterns. We tested the hypothesis that the highly temperaturetolerant intertidal green crab Carcinus maenas has a broader pejus range than the rock crab Cancer irroratus, which lives largely in the subtidal and moves only occasionally into the intertidal zone. The American lobster Homarus americanus, as an entirely subtidal animal, was hypothesized to have the narrowest pejus range. Subtidal habitats typically exhibit fewer and slower water-temperature fluctuations than intertidal habitats. We exposed the animals to a fast and progressive temperature challenge and measured parameters at the behavioral level, the whole-animal physiology level, and the cellular-molecular level. We used a broad set of whole-animal level and cellular parameters to identify $T_{\mathrm{p}}$ and $T_{\mathrm{C}}$.

\section{MATERIALS AND METHODS}

\section{Animals}

Adult rock crabs Cancer irroratus (Say, 1817) with an average carapace width of $9.3 \pm 1.3 \mathrm{~cm}$ (mean \pm SD) were acquired as bycatch in lobster traps by a local lobster fisherman in Saco, Maine. Adult intermolt green crabs Carcinus maenas (Linnaeus, 1758) with an average carapace width of $4.5 \pm 0.7 \mathrm{~cm}$ were collected by hand in the intertidal of Biddeford Pool, Maine. Adult hard shell lobsters Homarus americanus (Milne Edwards, 1837) with an average carapace length of $8.9 \pm 0.2 \mathrm{~cm}$ were trapped by a local lobster fisherman off Winter Harbor, Maine. All animals were collected during June and September of 2008 and 2009 and kept in a flowthrough seawater system in the Marine Science Center at the University of New England (UNE), with ambient seawater temperatures of 12 to $15^{\circ} \mathrm{C}$ and salinity 30 , and fed squid, mussels, and fish ad libitum. Animals were used for experimentation after at least $1 \mathrm{wk}$ of acclimation.

\section{Sequencing}

To design degenerate primers, we searched GenBank for AMPK protein sequences from various invertebrate and vertebrate species. Obtained sequences were aligned using the MultAlin tool (http:// bioinfo.genotoul.fr/multalin/multalin.html). Degenerate forward and reverse primers for PCR were designed based on highly conserved areas in the aligned sequences.

For all 3 species, total RNA from the hepatopancreas was purified using the Total RNA Isolation System (Promega) and reverse-transcribed (Super-Script First Strand Synthesis System, Invitrogen). We amplified cDNA with the respective primer pairs via PCR with an annealing temperature of $45^{\circ} \mathrm{C}$. Resulting bands were extracted and DNA purified using the MinElute Gel Extraction Kit (Qiagen). DNA was sequenced at the Mount Desert Island Biological Laboratory sequencing core facility (MDIBL, Salisbury Cove, ME) on an ABI 3100 sequencer. The obtained DNA sequences were converted to a predicted amino acid sequence using the NCBI open 
reading frame finder (www.ncbi.nlm.nih.gov/gorf/ gorf.html), and a BLAST search confirmed the cDNA as AMPK (as per the methods in Towle et al. 2001).

\section{Temperature incubations}

Animals (5 per species and time point) were placed overnight in a darkened $100 \mathrm{l}$ tank at $12^{\circ} \mathrm{C}$. The following day, animals were exposed to a fast, progressive temperature increase $\left(6^{\circ} \mathrm{C} \mathrm{h}^{-1}\right)$ and sacrificed at $12,14,16,18,20,22,24,26,28,30,32$, or $34^{\circ} \mathrm{C}$ (not all temperatures were used for each species). Animals were sacrificed at the respective temperature with a cut through the cerebral ganglion and the heart was removed and flash-frozen with Wollenberger tongs pre-cooled in liquid nitrogen. The flash-frozen samples were stored at $-80^{\circ} \mathrm{C}$. We focused on the heart tissue because a functioning circulatory system is crucial for maintaining proper oxygenation of the tissues, and failure of the heart due to heat stress is a key factor in the switch to anaerobiosis and the transition to the pejus range. Additionally, we chose the heart tissue based on preliminary work on lobsters showing that during heat stress, AMPK activity increased earlier in the heart than in the hepatopancreas or tail muscle (M. Frederich unpubl. data).

\section{Righting response}

The ability of each species to respond behaviorally to experimental stimulation at different temperatures was investigated by subjecting animals to the fast progressive temperature increase as described above ('Temperature incubations'). Throughout the temperature increase, animals were turned upside down underwater and placed on a flat surface. The reaction time to return to the upright position was monitored. Animals were considered 'not turning' if they failed to turn within $5 \mathrm{~min}$. Experiments were performed with no more than 3 animals per tank to provide sufficient space. Each animal was tested at all temperatures and species were tested separately to prevent species interaction.

\section{Heart rate}

Animal heart rate ( $\mathrm{n}=5$ per species) was monitored during temperature incubations using photoplethysmographs (iSiTEC) that were glued to the carapace above the heart, as described in detail by Depledge (1984) and Frederich \& Pörtner (2000), and connected to a digital recording device (PowerLab). Average heart rate was determined for each species every $2^{\circ} \mathrm{C}$ during heating by counting peaks manually over a $1 \mathrm{~min}$ period. For the temperature range in which the data follow a linear regression, the $Q_{10}$ was calculated using the equation from the respective regression.

\section{Lactate}

Lactate concentration, indicating the onset of anaerobiosis, was measured in the harvested heart tissue for each species using a photometric enzyme assay that quantifies the accumulation of NADH after converting lactate and NAD into pyruvate and NADH (Bergmeyer 1985) and normalized to protein concentration (Bradford 1976).

\section{Heat shock protein 70 levels and AMPK activity}

Total heat shock protein 70 (HSP70) levels, including both the constitutively expressed and the inducible form, and AMPK activity were quantified by Western blot analysis. AMPK activity was assessed as phosphorylation of AMPK at the T172 site of the alpha subunit. Tissue samples were ground under liquid nitrogen and homogenized using a buffer containing phosphatase inhibitors to prevent dephosphorylation of AMPK (for details see Frederich et al. 2009). Proteins were separated on a $7 \%$ polyacrylamide-SDS gel at $100 \mathrm{~V}$ for $2 \mathrm{~h}$. The proteins were then transferred to a nitrocellulose membrane at $70 \mathrm{~V}$ for $2 \mathrm{~h}$ and the membrane blocked with $5 \%$ non-fat dry milk in Tris-buffered saline with Tween 20 (TBST). Primary rabbit anti-pT172 antibodies (Upstate), mouse anti-HSP70 (Sigma), rabbit anti-actin (loading control, Cell Signaling), and secondary goat anti-rabbit or goat anti-mouse antibodies (BioRad) were used to probe for the respective proteins. The membranes were developed with the HyGlo ECL kit (Denville Scientific). Bands were quantified using Image-J software (NIH).

\section{Statistics}

Data were analyzed by a linear regression analysis to test whether the slope of the resulting regression line was significantly different from zero and 
whether significant differences between slopes exist (GraphPad InStat). Data were also analyzed for breakpoints using a Q-BASIC program for the identification of critical points (Yeager \& Ultsch 1989). A $p<0.05$ was considered significant. If no linear regression could be fit through the data and no breakpoint could be identified, we performed a 2-way ANOVA and a Tukey post hoc test to test for significant differences. Data are reported as mean \pm standard error.

\section{RESULTS}

\section{Sequencing}

Amplification with the primers F1 (5'-AAR YTN GTN GTN TTY GAY AC-3'), F2 (5'-AAY GGN GTN MGN GCN GCN CCN YTN T-3') and R4 (5'-YTC NGC NGC NAR RTT DAT NAC RTC RA-3') (where $\mathrm{Y}=\mathrm{T}$ or $\mathrm{C} ; \mathrm{R}=\mathrm{A}$ or $\mathrm{G} ; \mathrm{D}=\mathrm{A}$ or $\mathrm{G}$ or $\mathrm{T} ; \mathrm{N}=\mathrm{A}, \mathrm{G}, \mathrm{C}$, or $\mathrm{T})$, in the combination F1-R4 for green crab and F2$\mathrm{R} 4$ for rock crab and lobster yielded a sequenceable PCR product. We partially sequenced the AMPK gamma subunit to show that AMPK is actually expressed in the 3 decapod crustacean species. We obtained sequence fragments of 488, 540, and 561 base pairs for lobster, green crab, and rock crab, respectively (GenBank accession nos. JN134158, JN134159, and ACL13567.1, respectively). A complete sequence was not essential for this comparative study and therefore we did not attempt to obtain one. The overlapping translated amino acid sequence was conserved by $92.1 \%$. When comparing all 3 amino acid sequences to the sequence of the fruit fly Drosophila melanogaster (GenBank accession no. NP_ 732594.1), another arthropod species, $75 \%$ of the sequence fragment was still conserved and confirmed the previously reported high sequence conservation of AMPK.

\section{Righting response}

All animals, in all 3 species, were able to right themselves within 1 to $3 \mathrm{~s}$ after being turned on their back at $12^{\circ} \mathrm{C}$. With increasing water temperatures, the righting response slowed, and the temperature at which this occurred varied between species: rock crabs started to exhibit a slower response at $20^{\circ} \mathrm{C}$, the first animal stopped turning at $26^{\circ} \mathrm{C}$, and no animal was able to turn at $30^{\circ} \mathrm{C}$. Lobsters started to slow down at $28^{\circ} \mathrm{C}$, the first lobster stopped turning at $30^{\circ} \mathrm{C}$, and no lobster turned at $31^{\circ} \mathrm{C}$. Green crabs slowed down minimally over a broad temperature range. The first green crab stopped turning at $34^{\circ} \mathrm{C}$ and no green crab turned at $36^{\circ} \mathrm{C}$ (Fig. $1 \mathrm{~A}, \mathrm{~B}$ ). There-
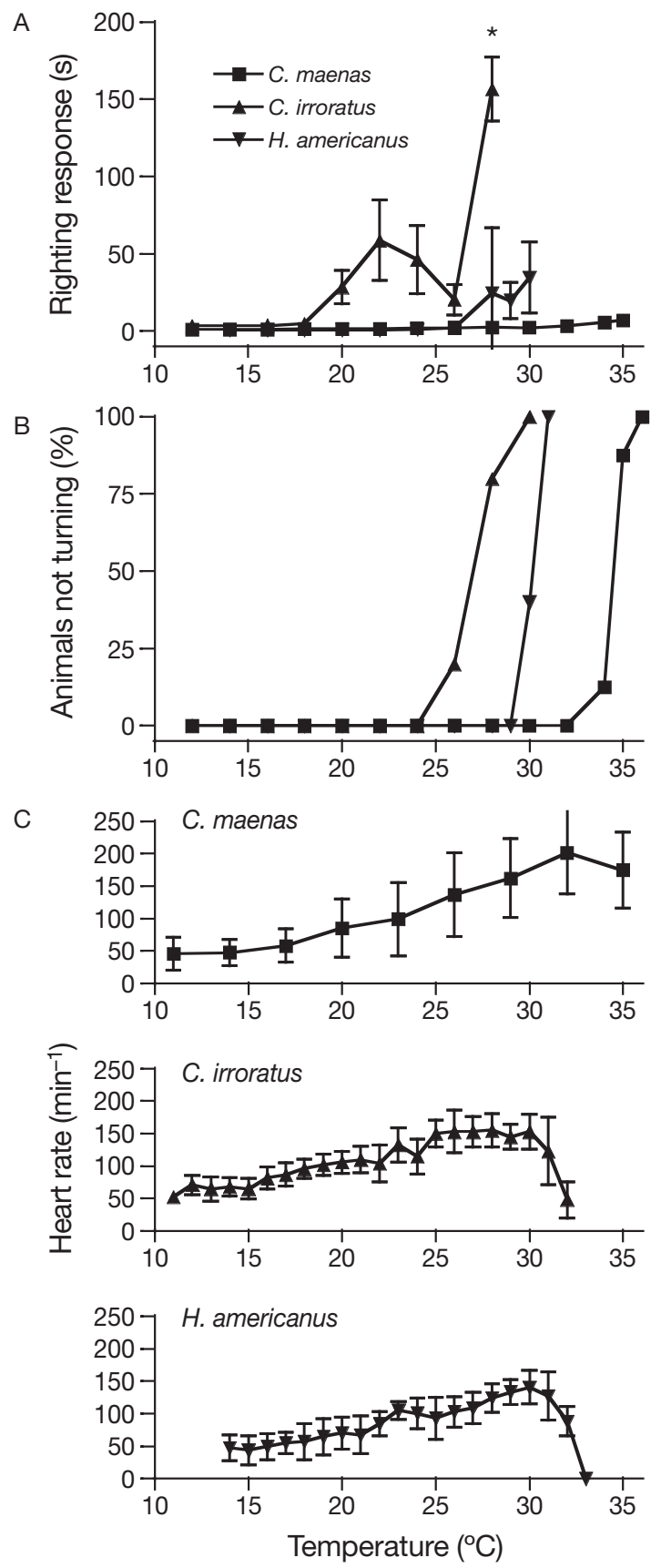

Fig. 1. Carcinus maenas, Cancer irroratus, and Homarus americanus. (A) Righting response, (B) animals not able to turn within $5 \mathrm{~min}$, and $(\mathrm{C})$ heart rate during exposure to a fast progressive temperature challenge. ${ }^{*}$ ANOVA: $p<0.05$ vs. $12^{\circ} \mathrm{C}$. Data are mean $\pm \mathrm{SE}$, with $\mathrm{n}=5$ per species and time point. Data for rock crab adapted with permission from Frederich et al. (2009) 
fore, the transition from a slower response to no response was gradual for rock crabs and lobsters. Conversely, for green crabs the transition from righting quickly to not turning occurred suddenly, with most green crabs still recovering quickly at $34^{\circ} \mathrm{C}$.

\section{Heart rate}

Heart rate increased with increasing temperature to an average maximum of $153 \pm 27$ beats $\mathrm{min}^{-1}$ at $28^{\circ} \mathrm{C}$ (rock crab), $141 \pm 25$ beats $\mathrm{min}^{-1}$ at $30^{\circ} \mathrm{C}$ (lobster), and $201 \pm 63$ beats $\min ^{-1}$ at $32^{\circ} \mathrm{C}$ (green crab; Fig. 1C). The $Q_{10}$ between 14 and $30^{\circ} \mathrm{C}$ was $1.57 \pm$ 0.08 for rock crab, $1.82 \pm 0.12$ for lobster, and 1.91 \pm 0.18 for green crab (mean \pm SEM). This range (14 to $30^{\circ} \mathrm{C}$ ) to calculate $Q_{10}$ was chosen because in this temperature range, heart rate follows a significant linear regression for all 3 species. When the heart rate was regressed on temperature, the slopes between 14 and $30^{\circ} \mathrm{C}$ did not differ between lobster and rock crab ( $p>0.05)$ but differed significantly between green crab and both other species $(\mathrm{p}<0.05)$.

\section{Lactate accumulation}

Lactate accumulation in the heart was induced by heat stress in all 3 species. In green crabs, lactate stayed constant between 12 and $32^{\circ} \mathrm{C}(11.6 \pm 3.3$ nmol $\mathrm{g}^{-1}$ protein), but increased significantly ( $\mathrm{p}<$ 0.05 ) at $34^{\circ} \mathrm{C}$ (Fig. $2 \mathrm{~A}$ ). In rock crabs, lactate was constant between 12 and $28^{\circ} \mathrm{C}\left(7.5 \pm 1.3 \mathrm{nmol} \mathrm{g}{ }^{-1}\right.$ protein) and increased significantly to $16.5 \pm 3.5 \mathrm{nmol}$ $\mathrm{g}^{-1}$ protein at $30^{\circ} \mathrm{C}(\mathrm{p}<0.05)$ (Fig. 2B). Due to the non-linear data in rock crabs and green crabs, we analyzed these data by ANOVA. In lobsters, lactate increased continuously from $3.8 \pm 2.7 \mathrm{nmol} \mathrm{g}^{-1}$ protein, following a linear regression with a slope that is significantly different from zero ( $p<0.05$ ) (Fig. 2C). Maximum lactate accumulation in lobsters was reached at $30^{\circ} \mathrm{C}\left(13.9 \pm 5.4 \mathrm{nmol} \mathrm{g}^{-1}\right.$ protein $)$. Therefore, the transition to anaerobic metabolism occurred between 32 and $34^{\circ} \mathrm{C}$ for green crabs and between 28 and $30^{\circ} \mathrm{C}$ for rock crabs. A sudden transition to anaerobiosis could not be detected for lobsters.

\section{Heat shock proteins}

HSP70 protein levels remained constant in green crabs and rock crabs throughout the chosen temper- ature range (Fig. 3A,B). A linear regression through the data was not significantly different from zero $(\mathrm{p}>$ 0.05). In lobsters, a linear regression did have a slope significantly different from zero $(p<0.05)$ and was significantly different from the other 2 species (Fig. 3C).

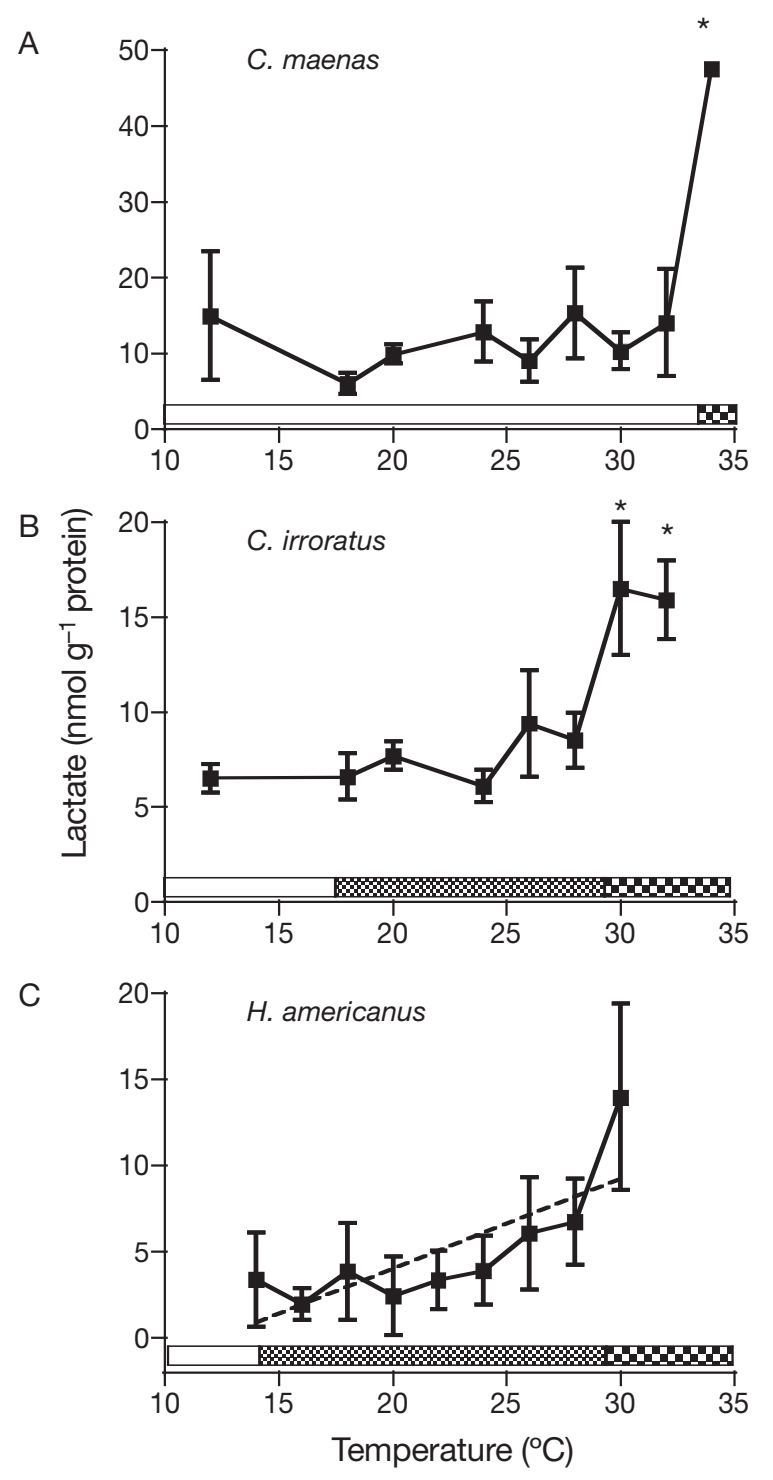

Fig. 2. Carcinus maenas, Cancer irroratus, and Homarus americanus. Lactate accumulation in the heart during exposure to a fast progressive temperature challenge for (A) green crab, (B) rock crab, and (C) American lobster. ${ }^{*}$ ANOVA: $\mathrm{p}<0.05$ vs. $12^{\circ} \mathrm{C}$. Dashed line indicates linear regression with slope significantly different from zero $(\mathrm{p}<0.05)$. Data are mean $\pm \mathrm{SE}$, with $\mathrm{n}=5$ per species and time point. Data for rock crab adapted with permission from Frederich et al. (2009). Optimum, pejus, and pessimum ranges deduced from all evaluated parameters are indicated for each species by a white, dotted, and chequered box, respectively 
A
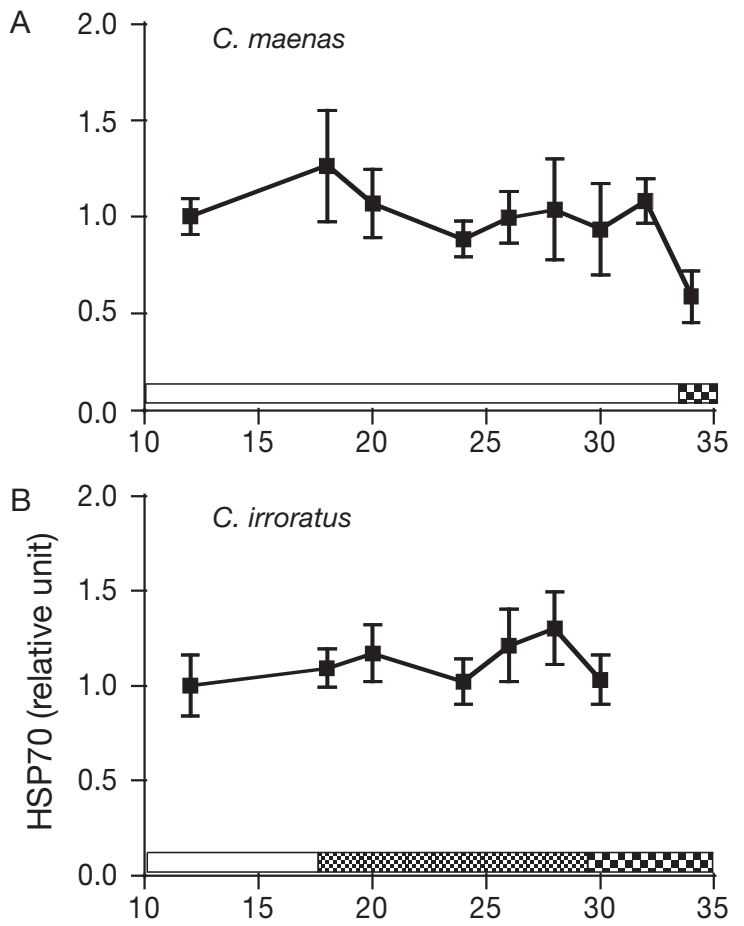

C

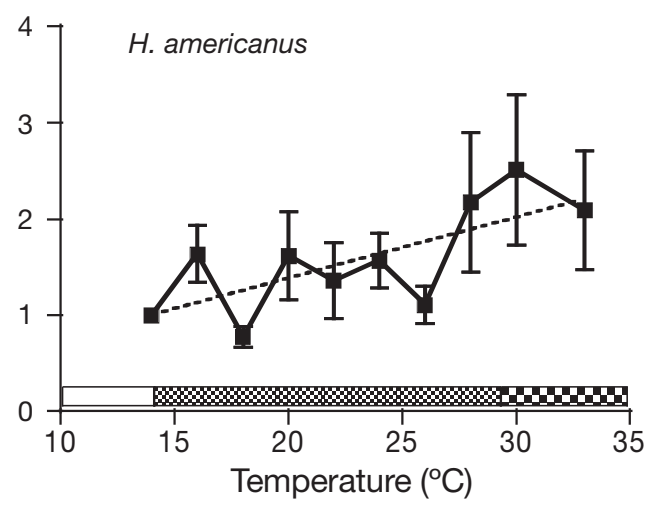

Fig. 3. Carcinus maenas, Cancer irroratus, and Homarus americanus. Heat shock protein 70 (HSP70) levels during exposure to a fast progressive temperature challenge for (A) green crab, (B) rock crab, and (C) American lobster. Data are mean $\pm \mathrm{SE}$, with $\mathrm{n}=5$ per species and time point. Dashed line indicates linear regression with slope significantly different from zero $(p<0.05)$. Data for rock crab adapted with permission from Frederich et al. (2009). Optimum, pejus, and pessimum ranges deduced from all evaluated parameters are indicated for each species by a white, dotted, and chequered box, respectively

\section{AMPK activity}

AMPK activity remained constant in green crabs throughout the range of temperatures tested. No significant differences (linear regression analysis, $\mathrm{p}>$ 0.05) were detected (Fig. 4A). In rock crabs, AMPK activity remained low at 12 and $18^{\circ} \mathrm{C}$, but increased sharply above $18^{\circ} \mathrm{C}$. Data was analyzed to determine
A

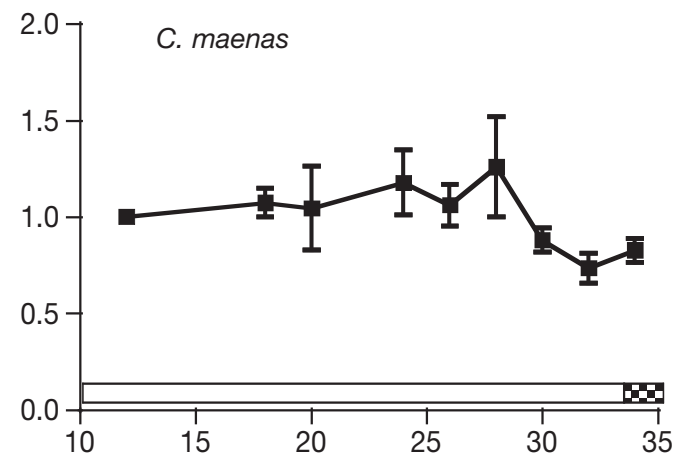

B

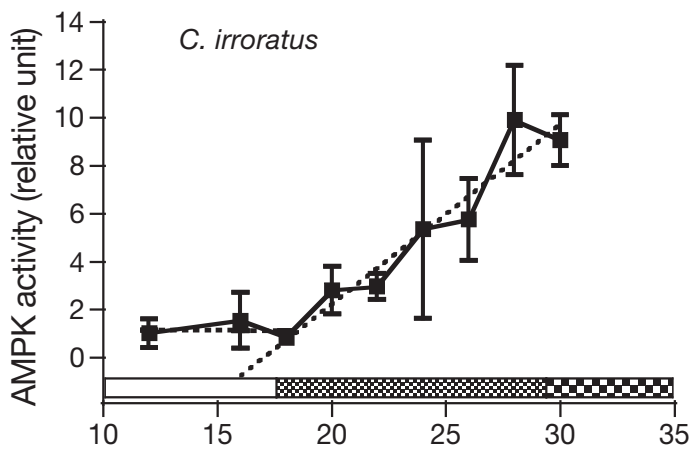

C

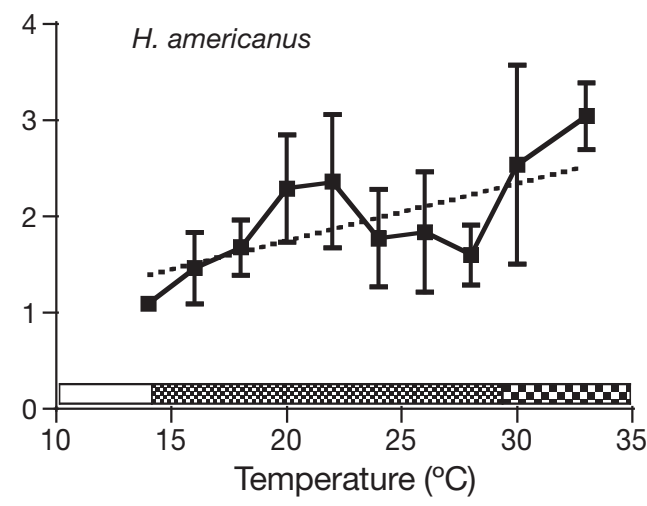

Fig. 4. Carcinus maenas, Cancer irroratus, and Homarus americanus. AMP-activated protein kinase (AMPK) activity during exposure to a fast progressive temperature challenge for (A) green crab, (B) rock crab, and (C) American lobster. Data are mean $\pm S E$, with $n=5$ per species and time point. Dashed line indicates linear regression with slope significantly different from zero $(p<0.05)$. For rock crabs, 2 lines significantly different to each other intersect at $18.5^{\circ} \mathrm{C}$ (see 'Results' for details). Data for rock crab adapted with permission from Frederich et al. (2009). Optimum, pejus, and pessimum ranges deduced from all evaluated parameters are indicated for each species by a white, dotted, and chequered box, respectively

the 2 best-fit regressions through the data and the intersection of these regressions (Yeager \& Ultsch 1989). For the rock crabs, there are 2 significantly different linear regressions that intersect at $18.5^{\circ} \mathrm{C}$, and therefore $18.5^{\circ} \mathrm{C}$ is identified as a breakpoint (Fig. 4B). In lobsters, a continuous increase in AMPK 
activity was observed by a regression analysis that showed a linear increase with a slope significantly different from zero ( $p<0.05$ ) (Fig. 4C).

\section{Critical and pejus temperatures}

$T_{\mathrm{C}}$ was identified as the temperature at which the animals switch to anaerobic metabolism and reach their maximum heart rate. $T_{\mathrm{C}}$ was attained between 32 and $34^{\circ} \mathrm{C}$ for green crabs, and between 28 and $30^{\circ} \mathrm{C}$ for both rock crabs and lobsters. $T_{\mathrm{p}}$, the threshold at which animals enter the pejus range, in which survival is possible with a limited scope for activity, was identified by a combination of parameters, including declining motor activity (reaction time), increasing lactate accumulation, increasing AMPK activity, and HSP70 accumulation. For rock crabs, we identified $T_{\mathrm{p}}$ to be between 18 and $20^{\circ} \mathrm{C}$ based on the sudden onset of AMPK activity and a gradual slowing down in the righting response (Table 1). For lobsters, we identified $T_{\mathrm{p}}$ above $14^{\circ} \mathrm{C}$ based on the continuous increase in lactate and HSP70 protein accumulation and AMPK activity. Additionally, righting response declined well before $T_{\mathrm{C}}$ for lobsters. For green crabs, we could not identify a $T_{\mathrm{p}}$. All parameters remained unchanged until reaching $T_{\mathrm{c}}$. Therefore, we can either set $T_{\mathrm{p}}$ at $T_{\mathrm{c}}$ or assume that $T_{\mathrm{p}}$ does not exist for green crabs.

\section{DISCUSSION}

In the present study, we used a combination of heart rate, lactate accumulation, the righting response, HSP70 levels, and AMPK activity to identify $T_{\mathrm{C}}, T_{\mathrm{p}}$, and the respective pejus range for 3 crustacean species with respect to aquatic thermal stress. Based on the different thermal stabilities in their respective habitats, we expected to see differences in the width of the pejus range among the 3 species. However, our hypothesis that the intertidal green crab has a broader pejus range to tolerate larger temperature fluctuations more easily was not supported. The green crab switches abruptly from optimum to pessimum, without a range of diminishing performance that would represent the pejus range. This abrupt switch was observed in parameters at the whole-animal level and at the cellular level.
The somewhat crude measure for whole-animallevel performance, the righting resonse, indicated for green crabs a sudden transition from being highly active to heat torpor. The cellular parameters match this observation. In green crabs, no increase in AMPK activity could be detected at all, even after severe and finally deadly heat stress. This is in stark contrast to the lobsters, where a continuous increase in AMPK activity occurred with temperature, and the rock crabs, where AMPK activity remained low at lower temperatures, but increased sharply during heat stress. These findings are consistent with the accumulation of lactate: in green crabs, lactate accumulation was observed only close to a lethal temperature; in rock crabs, lactate remained low throughout moderate temperatures, and then accumulated sharply at higher temperatures; and in lobsters, continuous lactate accumulation throughout the temperature range occurred.

Accumulation of HSP70 was only seen in lobsters. Neither in rock crabs nor in green crabs could any increase in HSP70 be detected. The main regulation of HSP70 occurs by transcription (for review see Feder \& Hofmann 1999). Consequently, changes in HSP70 levels are often detected hours after the actual heat stress or especially during recovery from a heat stress (e.g. Tomanek \& Somero 1999, Tomanek 2005). Furthermore, an upper thermal limit for the HSP synthesis has been detected in snails at about the highest body temperature that the animals experience (Tomanek \& Somero 1999, Tomanek 2010). Therefore, the combination of a rapid rate of increase 
and the overall degree of temperature change in the present study may have prevented a substantial heat shock response. Because AMPK is activated by accumulation of cellular free AMP and by phosphorylation through an upstream kinase (AMPK-kinase), it can respond more rapidly to changes in the cellular energy status. The considerations above in conjunction with the high conservation of AMPK during evolution, its rapid activation, and its activation through changes in the cellular energy state, make AMPK a promising marker for immediate stress that affects cellular energetics. Clearly, HSP70 and AMPK play different roles during stressful environmental conditions. HSP70 prevents heat-induced denaturing of proteins, and aids in refolding of denatured proteins. This highly ATP-consuming process is crucial for the survival of an animal in most environments and consequently nearly all animals, with very few exceptions (Hofmann et al. 2000), exhibit this mechanism. Similarly conserved, the AMPK cascade monitors the cellular ATP pool. Because cellular ATP is depleted, or at least starts to diminish, before heat-induced protein damage and a subsequent HSP70 increase occurs, AMPK activity is likely to be an earlier alarm signal for temperature stress. To our knowledge, no study has yet addressed whether the 2 pathways affect each other directly. Therefore, it remains a speculation that activation of AMPK could supply the ATP required by HSP70 to fulfill its energyconsuming function.

Differences in $T_{\mathrm{p}}$ and the pejus range seem to reflect the respective habitat of the investigated species. Rock crabs, green crabs, and lobsters are widely distributed along the coastal regions in the northwest Atlantic and live in an overlapping habitat. These 3 crustacean species feed on a common suite of prey (Ojeda \& Dearborn 1991), and are often considered to be part of a feeding guild (HilleRisLambers \& Dieckmann 2003), with intraguild predation as well. However, in summer, green crabs will forage in the intertidal zone during high tide and they often seek refuge under rocks or in tidepools during low tide, which potentially exposes them to increasing water and air temperatures. For example, at our green crab collection site (Biddeford Pool), we measured temperatures up to $37.8^{\circ} \mathrm{C}$ on sun-exposed rocks during a hot summer day, with surface water temperatures of $15^{\circ} \mathrm{C}$. Additionally, previous studies on intertidal invertebrate species have shown that body temperature can vary up to $20^{\circ} \mathrm{C}$ during one tidal cycle as a result of aerial exposure during low tide (Helmuth 1998), and that body temperatures during emersion can cause physiological damage (e.g. Hofmann \& Somero 1995, Stillman 2003), suggesting that body temperatures may be close to the animal's upper thermal limits during low tide. While we did not examine the effects of increasing aerial temperature versus aquatic exposure, previous work on an intertidal mussel shows that the upper lethal temperature for summer acclimated animals was within $0.5^{\circ} \mathrm{C}$ for both aerial and aquatic exposures (Jones et al. 2009), suggesting that our results are relevant for both high aerial and aquatic temperatures. While juvenile lobsters will often coincide with the abundant green crabs in the tidepools of the rocky intertidal, adult lobsters and rock crabs live mainly in the subtidal, and therefore, these animals are less likely to experience highly variable thermal regimes. In southern Casco Bay, where most of the animals for the present study were caught, the average bottom-water temperature from 2005 to 2009 as measured by data loggers attached to lobster traps was around $10^{\circ} \mathrm{C}$, with a minimum of $4.4^{\circ} \mathrm{C}$, and a maximum of $17.8^{\circ} \mathrm{C}$ (data from www.eMOLT.org, trap no. RP01). Data from traps at different depths in the same area show similar maximum temperatures (Table 2). While temperatures in this area are relatively stable and change only seasonally, rare faster temperature swings of up to $15^{\circ} \mathrm{C}$ within several hours have been reported (Manning \& Pelletier 2009).

In their subtidal habitat, and during infrequent occurrences in the lower intertidal, lobsters and rock crabs can be exposed to their respective $T_{\mathrm{p}}$. The activation of AMPK helps to match the increased energy

Table 2. Maximum water temperature off the Maine coast in southern Casco Bay, recorded by data loggers connected to lobster traps. Data from Environmental Monitors on Lobster Traps (eMOLT); see www.emolt.org for specifics on trap locations and data sampling method

\begin{tabular}{|lccc|}
\hline $\begin{array}{l}\text { Trap } \\
\text { no. }\end{array}$ & $\begin{array}{c}\text { Maximum water } \\
\text { temp. }\left({ }^{\circ} \mathrm{C}\right)\end{array}$ & $\begin{array}{c}\text { Depth } \\
(\mathrm{m})\end{array}$ & $\begin{array}{c}\text { Date } \\
(\mathrm{mm} / \mathrm{dd} / \mathrm{yy})\end{array}$ \\
\hline PW01 & 18.3 & 12.8 & $8 / 11 / 04$ \\
RP01 & 17.8 & 16.5 & $8 / 11 / 04$ \\
ST03 & 17.8 & 11.0 & $7 / 23 / 08$ \\
ET02 & 15.9 & 21.9 & $8 / 8 / 08$ \\
ZW02 & 15.6 & 14.6 & $9 / 19 / 03$ \\
DJ03 & 15.2 & 14.6 & $9 / 9 / 04$ \\
KS01 & 14.3 & 18.3 & $9 / 19 / 04$ \\
ST02 & 13.6 & 31.1 & $8 / 9 / 08$ \\
DJ02 & 11.8 & 40.2 & $10 / 4 / 03$ \\
DJ01 & 10.2 & 95.1 & $10 / 29 / 05$ \\
ST01 & 9.0 & 53.0 & $8 / 26 / 08$ \\
\hline
\end{tabular}


demand that arises with an increased metabolic rate at higher temperatures. Both species share a fairly similar habitat, but show some differences in how the measured parameters change during heat stress. This might be due to their different evolutionary history. Both species evolved in different clades and under different environmental conditions. While the group of Homarida, which includes the lobster, is thought to have evolved in the early Triassic ( 210 to 230 million yr ago [mya]), the group of Brachyura, which includes the rock crab, is thought to have evolved in the warmer Jurassic period $(\sim 150$ to 210 mya; reviewed in Patek et al. 2007). The different evolutionary past will likely affect physiological performance. However, the general trend of exhibiting a well-defined pejus range is similar. On the other hand, the intertidal green crab, a brachyuran crab, is much more likely to experience both aerial and aquatic temperatures close to its $T_{\mathrm{c}}$, or above the $T_{\mathrm{p}}$ of the lobster and the rock crab. The very dynamic environment of the intertidal zone makes it necessary for the green crab to remain active even during higher temperatures. It seems that $T_{\mathrm{p}}$ shifts very close to $T_{\mathrm{C}}$ in green crabs and therefore the pejus range was eliminated (Fig. 5). To our knowledge, all previous studies that identified $T_{\mathrm{c}}$ and $T_{\mathrm{p}}$ in various marine invertebrates show a pejus range that spans several degrees (Table 3, and citations therein). However, none of the species for which a pejus range was defined lives in a habitat that shows high environmental variability associated with the intertidal zone.

Enhanced thermal sensitivity of the circulatory system might be a potential mechanism to retain high activity despite increasing temperature. Green crabs exhibited a significantly higher $Q_{10}$ for their increase

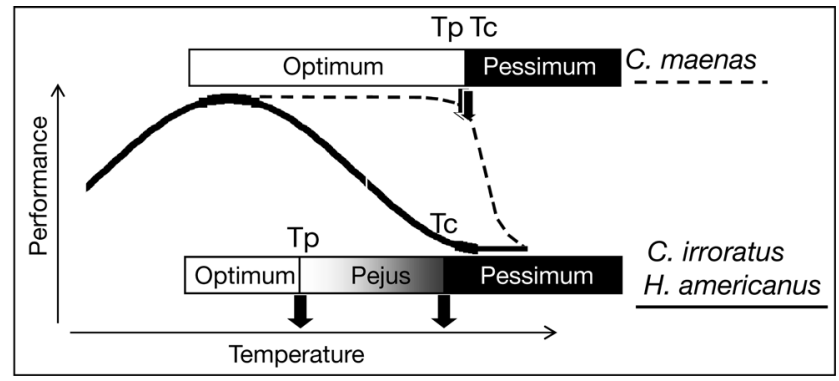

Fig. 5. Schematic model that shows the optimum, pejus, and pessimum range, as well as the respective thresholds of critical $\left(T_{\mathrm{c}}\right)$ and pejus $\left(T_{\mathrm{p}}\right)$ temperature. In most species, like Cancer irroratus and Homarus americanus (solid line), a gradual decrease in scope for aerobic activity ('performance'), concomitant with an increase in AMP-activated protein kinase (AMPK) activity, occurs in the pejus range between $T_{\mathrm{c}}$ and $T_{\mathrm{p}}$. In Carcinus maenas (dashed line), performance changes rapidly from maximum (optimum) to minimum (pessimum) without a detectable pejus range. This elimination of the pejus range might be an adaptive strategy to survive in highly variable habitats, such as the intertidal zone

in heart rate with temperature, and a higher maximum heart rate, compared to rock crabs and lobsters. This enhanced scope to increase cardiac performance might allow the peripheral tissues to be supplied with oxygen more efficiently, maintaining aerobic metabolism at higher temperatures. Additionally, lactate concentration in the green crabs' hearts at control conditions was higher than in the other 2 species. This pattern might reflect a higher metabolic baseline activity of the heart with a concomitant increased spillover of lactate production from the potentially accelerated glycolytic pathway. Baseline AMPK activity, as well as AMPK mRNA and

Table 3. Pejus $\left(T_{\mathrm{p}}\right)$ and critical $\left(T_{\mathrm{c}}\right)$ temperatures and the respective pejus range for several marine invertebrate and fish species; not detected

\begin{tabular}{|lcccl|}
\hline Species & $T_{\mathrm{p}}$ & $T_{\mathrm{c}}$ & Pejus range & Source \\
\hline Carcinus maenas (crustacean) & $32-34$ & $32-34$ & nd & Present study \\
Homarus americanus (crustacean) & $14-16$ & $28-30$ & $12-16$ & Present study \\
Cancer irroratus (crustacean) & $18-20$ & $28-30$ & $8-12$ & Present study, Frederich et al. (2009) \\
Taliepus dentatus larvae (crustacean) & 15 & 19 & 4 & Storch et al. (2009) \\
Cancer pagurus (crustacean) & $16-17$ & $>20$ & $>3$ & Metzger et al. (2007) \\
Gadus morhua (cod) & 16 & 22 & 6 & Pörtner \& Knust (2007) \\
Laternula elliptica (bivalve) & 4.3 & 6 & 1.7 & Pörtner et al. (2006) \\
Gadus morhua (cod) & 7.3 & 16 & 8.7 & Lannig et al. (2004) \\
Zoarces viviparus (eelpout) & $13-15$ & 22.5 & $7.5-9.5$ & Zakhartsev et al. (2003) \\
Pachycara brachycephalum (Antarctic teleost) & 7 & 12 & 5 & Mark et al. (2002) \\
Maja squinado (crustacean) & 17 & 30 & 13 & Frederich \& Pörtner (2000) \\
\hline
\end{tabular}


HSP70 mRNA expression measured by quantitative real-time PCR in the heart, were similar between the 3 investigated species (data not shown). This is in contrast to a study comparing sub- and supra-littoral amphipods Gammarus oceanicus and Orchestia gammarellus, respectively (Bedulina et al. 2010), which found elevated baseline levels of HSP70 protein in the supra-littoral species and interprets this as an evolutionary adaptation to the more stressful environment. Similarly, Tomanek (2010) indicates that subtidal animals have a wide range of temperatures over which they can synthesize HSPs, while intertidal animals that are living close to their upper thermal limits have a reduced ability to acclimate further to increased temperatures. More specifically, Tomanek (2010) and Somero (2010) report that in different intertidal snail species the temperature thresholds that induce HSP70 accumulation vary with their respective positioning in the intertidal. More heatexposed animals switch on the HSP70-generating pathways at higher temperatures. However, the ability to acclimate to higher temperatures than those seen in the natural habitat was diminished in the most heat-tolerant species. A similar pattern is reported for porcelain crab species (Stillman 2003). These findings indicate that several intertidal species are already living at their thermal maximum, and a further increase in temperature (e.g. by global climate change) might be deleterious for the respective species. It is very unlikely that the green crab Carcinus maenas will be exposed to its aquatic $T_{\mathrm{c}}$ in Maine, and even aerial exposures to $T_{\mathrm{c}}$ are unlikely to occur on a regular basis. Therefore, it seems that the green crab does not live at its thermal maximum in Maine. However, the abrupt transition from optimum to pessimum at high temperatures indicates that if they reach $T_{\mathrm{c}}$ in the environment, heat coma and death will occur suddenly. We did not investigate whether this threshold can shift with acclimation. Seeing that other species trade the ability to live in a highly variable environment with the ability to acclimate (Somero 2010), we think that the acclimation ability for $C$. maenas is doubtful. This interpretation is also supported by a recent study on the adaptation potential in copepods (Kelly et al. 2012). Copepods from a broad latitudinal gradient were reared at high temperatures for 10 generations and did not show an increase in heat tolerance. Therefore, the ability of the intertidal green crab to adapt to increased temperatures by acclimation might be limited.

Two other factors were not included in the present study: larval development and animal size. We worked with adult animals only and therefore can apply our interpretations to adult animals only. Storch et al. (2011) recently reported that thermal tolerance varies among larval stages in the Chilean kelp crab Taliepus dentatus, with the narrowest range of thermal tolerance in the megalopa stage. In that study, $T_{\mathrm{c}}$ and $T_{\mathrm{p}}$ seemed to shift together between larval stages with a constantly wide pejus range. Whether the same is true in the crustacean species investigated in the present study remains to be investigated.

The adults of green crabs, rock crabs, and lobsters used in our experiments were of different sizes and one could speculate that this affects their thermal tolerance. In separate experiments (data not shown), we inserted thermocouples into the animals and confirmed that throughout the fast prograssive temperature increase the body temperature is similar to the temperature of the incubation tank. Assuming that due to allometric scaling, smaller animals have a higher metabolic rate per gram of tissue, one could argue that green crabs should be more susceptible to temperature-induced energetic challenges than lobsters. However, our experiments showed exactly the opposite, green crabs being less affected by thermal stress. Therefore, we do not expect animal size to play a major role in the interpretation of our results that the green crabs eliminated the pejus range to expand their thermal window in their habitat.

The physiological, biochemical, or molecular mechanisms that make the elimination of the pejus range in the green crab possible is still unclear. However, the described shift of $T_{\mathrm{p}}$ to $T_{\mathrm{c}}$ and the elimination of the pejus range represent a new concept for tolerating a wide range of rapidly changing temperatures. We have previously argued that AMPK might be used as a marker for temperature stress in marine invertebrates (Frederich et al. 2009). The present study shows that this approach is feasible for species that live in a stable environment. However, it might not be efficacious for a species from the highly variable intertidal zone. Therefore, physiological markers and indicator species need to be selected very carefully, and with a detailed understanding of the underlying physiology at both the organismal and the cellular and molecular levels.

Acknowledgements. This study was funded by National Science Foundation (NSF) grant IOB-0640478 to M.F., and a summer research fellowship from the American Physiological Society to S.M.P. The authors thank lobster boat captains R. Collard and R. Bragdon for kindly providing animals, C. Toombs for analyzing the eMOLT data, and Dr. P. O. Yund for his help with the manuscript. This is UNE Marine Science Center publication no. 40. 


\section{LITERATURE CITED}

Bedulina DS, Zimmer M, Timofeyev MA (2010) Sub-littoral and supra-littoral amphipods respond differently to acute thermal stress. Comp Biochem Physiol B 155: 413-418

Bergmeyer HU (1985) Methods for enzymatic analysis, 3rd edn. VCH, Weinheim

Bradford MM (1976) A rapid and sensitive method for the quantitation of microgram quantities of protein utilizing the principle of protein-dye binding. Anal Biochem 72: 248-254

> Depledge MH (1984) Photoplethysmography-a non-invasive technique for monitoring heart beat and ventilation rate in decapod crustaceans. Comp Biochem Physiol A 77:369-371

- Feder ME, Hofmann GE (1999) Heat shock proteins, molecular chaperones, and the stress response: evolutionary and ecological physiology. Annu Rev Physiol 61:243-282

> Frederich M, Pörtner HO (2000) Oxygen limitation of thermal tolerance defined by cardiac and ventilatory performance in spider crab Maja squinado. Am J Physiol Regul Integr Comp Physiol 279:R1531-R1538

Frederich M, O'Rourke MR, Furey NB, Jost JA (2009) AMPactivated protein kinase (AMPK) in the rock crab, Cancer irroratus: an early indicator of temperature stress. J Exp Biol 212:722-730

> Hardie DG (2011) Energy sensing by the AMP-activated protein kinase and its effects on muscle metabolism. Proc Nutr Soc 70:92-99

Helmuth BST (1998) Intertidal mussel microclimates: predicting the body temperature of a sessile invertebrate. Ecol Monogr 68:51-74

HilleRisLambers R, Dieckmann U (2003) Competition and predation in simple food webs: intermediately strong trade-offs maximize coexistence. Proc R Soc Lond B Biol Sci 270:2591-2598

> Hofmann GE, Somero GN (1995) Evidence for protein damage at environmental temperatures: seasonal changes in levels of ubiquitin conjugates and HSP70 in the intertidal mussel Mytilus trossulus. J Exp Biol 198:1509-1518

> Hofmann GE, Buckley BA, Airaksinen S, Keen JE, Somero GN (2000) Heat-shock protein expression is absent in the Antarctic fish Trematomus bernacchii (family Nototheniidae). J Exp Biol 203:2331-2339

> Jones SJ, Mieszkowksa N, Wethey DS (2009) Linking thermal tolerances and biogeography: Mytilus edulis (L.) at its southern limit on the east coast of the United States. Biol Bull (Woods Hole) 217:73-85

Karagounis LG, Hawley JA (2009) The 5 adenosine monophosphate-activated protein kinase: regulating the ebb and flow of cellular energetics. Int J Biochem Cell Biol 41:2360-2363

Kelly MW, Sanford E, Grosberg RK (2012) Limited potential for adaptation to climate change in a broadly distributed marine crustacean. Proc R Soc B Biol Sci 279:349-356

Lannig G, Bock C, Sartoris FJ, Pörtner HO (2004) Oxygen limitation of thermal tolerance in cod, Gadus morhua L., studied by magnetic resonance imaging and on-line venous oxygen monitoring. Am J Physiol Regul Integr Comp Physiol 287:R902-R910

Manning J, Pelletier E (2009) Environmental monitors on lobster traps (eMOLT): long-term observations of New England's bottom-water temperatures. J Oper Oceanogr $2: 25-33$
Mark FC, Bock C, Pörtner HO (2002) Oxygen-limited thermal tolerance in Antarctic fish investigated by MRI and ${ }^{31}$ P-MRS. Am J Physiol Regul Integr Comp Physiol 283: R1254-R1262

> Metzger R, Sartoris FJ, Langenbuch M, Pörtner HO (2007) Influence of elevated $\mathrm{CO}_{2}$ concentrations on thermal tolerance of the edible crab Cancer pagurus. J Therm Biol 32:144-151

Ojeda FP, Dearborn JH (1991) Feeding ecology of benthic mobile predators: experimental analyses of their influence in rocky subtidal communities of the Gulf of Maine. J Exp Mar Biol Ecol 149:13-44

Patek SN, Feldmann RM, Porter M, Tshudy D (2007) Phylogeny and evolution. In: Phillis BF (ed) Lobsters; biology, management, aquaculture and fisheries. Blackwell Publishing, Oxford, p 113-145

Pörtner HO (2002) Physiological basis of temperaturedependent biogeography: trade-offs in muscle design and performance in polar ectotherms. J Exp Biol 205: 2217-2230

Pörtner HO (2010) Oxygen- and capacity-limitation of thermal tolerance: a matrix for integrating climate-related stressor effects in marine ecosystems. J Exp Biol 213: 881-893

Pörtner HO, Knust R (2007) Climate change affects marine fishes through the oxygen limitation of thermal tolerance. Science 315:95-97

> Pörtner HO, Peck LS, Hirse T (2006) Hyperoxia alleviates thermal stress in the Antarctic bivalve, Laternula elliptica: evidence for oxygen limited thermal tolerance. Polar Biol 29:688-693

Shelford VE (1931) Some concepts of bioecology. Ecology 12:455-467

Somero GN (2010) The physiology of climate change: how potentials for acclimatization and genetic adaptation will determine 'winners' and 'losers'. J Exp Biol 213:912-920

Stillman JH (2003) Acclimation capacity underlies susceptibility to climate change. Science 301:65

Storch D, Santelices P, Barria J, Cabeza K, Pörtner HO, Fernández M (2009) Thermal tolerance of crustacean larvae (zoea I) in two different populations of the kelp crab Taliepus dentatus (Milne-Edwards). J Exp Biol 212: 1371-1376

Storch D, Fernández M, Navarrete SA, Pörtner HO (2011) Thermal tolerance of larval stages of the Chilean kelp crab Taliepus dentatus. Mar Ecol Prog Ser 429:157-167

Tomanek L (2005) Two-dimensional gel analysis of the heatshock response in marine snails (genus Tegula): interspecific variation in protein expression and acclimation ability. J Exp Biol 208:3133-3143

Tomanek L (2010) Variation in the heat shock response and its implication for predicting the effect of global climate change on species' biogeographical distribution ranges and metabolic costs. J Exp Biol 213:971-979

Tomanek L, Somero GN (1999) Evolutionary and acclimation induced variation in the heat-shock responses of congeneric marine snails (genus Tegula) from different thermal habitats: implications for limits of thermotolerance and biogeography. J Exp Biol 202:2925-2936

> Towle DW, Paulsen RS, Weihrauch D, Kordylewski M, Salvador C, Lignot JH, Spanings-Pierrot C (2001) $\mathrm{Na}^{+}+\mathrm{K}^{+}$ATPase in gills of the blue crab Callinectes sapidus: cDNA sequencing and salinity-related expression of $\alpha$ subunit mRNA and protein. J Exp Biol 204:4005-4012

> Winder WW, Hardie DG (1999) AMP-activated protein 
kinase, a metabolic master switch: possible roles in type 2 diabetes. Am J Physiol 277:E1-10

Yeager DP, Ultsch GR (1989) Physiological regulation and conformation: a BASIC program for the determination of critical points. Physiol Zool 62:888-907

Zakhartsev MV, DeWachter B, Sartoris FJ, Pörtner HO, Blust

Editorial responsibility: Inna Sokolova,

Charlotte, North Carolina, USA
R (2003) Thermal physiology of the common eelpout (Zoarces viviparus). J Comp Physiol B 173:365-378

Zielinski S, Pörtner HO (1996) Energy metabolism and ATP free-energy change of the intertidal worm, Sipunculus nudus, below a critical temperature. J Comp Physiol B 166:492-500

Submitted: December 8, 2010; Accepted: September 1, 2011 Proofs received from author(s): December 27, 2011 